\title{
Antioxidant activities and bioactive components in some berries
}

\author{
Jacek Namiesnik $\cdot$ Kann Vearasilp • Magdalena Kupska • \\ Kyung-Sik Ham $\cdot$ Seong-Gook Kang $\cdot$ Yang-Kyun Park • \\ Dinorah Barasch · Alina Nemirovski · Shela Gorinstein
}

Received: 6 March 2013/Revised: 27 May 2013/Accepted: 1 June 2013/Published online: 20 July 2013

(C) The Author(s) 2013. This article is published with open access at Springerlink.com

\begin{abstract}
The objective of this study was to evaluate the antioxidant and binding effects of gooseberry, a less-studied berry, and to compare with blueberry and cranberry in the model of interaction with human serum albumin (HSA). The relationship between the scavenging properties of dietary polyphenols of the selected berries and their affinities for HSA were investigated by fluorescence analysis. In order to perform the extraction and identification of the antioxidants present in the samples, different types of extraction solvents were used, such as water, ethyl acetate, and diethyl ether. The polyphenols, tannins, anthocyanins and ascorbic acid contents, and the total antioxidant capacities (TACs) of the berry extracts were assessed by
\end{abstract}

S. Gorinstein: This article was written in memory of my dear brother Prof. Simon Trakhtenberg, who died in November 2011, who encouraged me and all our scientific group during all his life.

S. Gorinstein is affiliated with the David R. Bloom Center for Pharmacy.

J. Namiesnik $(\bowtie) \cdot$ M. Kupska

Department of Analytical Chemistry, Chemical Faculty,

Gdańsk University of Technology, 80952 Gdańsk, Poland

e-mail: chemanal@pg.gda.pl

K. Vearasilp

Faculty of Pharmacy, Srinakharinwirot University, Bangkok,

Thailand

K.-S. Ham · S.-G. Kang · Y.-K. Park

Department of Food Engineering, Mokpo National University,

Muan, Jeonnam, South Korea

D. Barasch · A. Nemirovski · S. Gorinstein $(\bowtie)$

The Institute for Drug Research, School of Pharmacy,

Hadassah Medical School, The Hebrew University,

91120 Jerusalem, Israel

e-mail: shela.gorin@mail.huji.ac.il using ESI-MS, FTIR, and radical scavenging assays. The contents of bioactive compounds and the levels of TACs in water extracts differed significantly and were the highest in water extracts in comparison with other extracts in all the investigated berries $(P<0.05)$. Gooseberry water extracts contained: polyphenols (mg GAE/g DW) $-5.37 \pm 0.6$, tannins (mg CE/g DW) $-0.71 \pm 0.2$, anthocyanins (mg $\mathrm{CGE} / \mathrm{g} \mathrm{DW})-12.0 \pm 1.2$, ascorbic acid (mg AA/g DW)— $5.15 \pm 0.5$, and TACs ( $\mu$ MTE/g DW) by ABTS and FRAP assays were $15.53 \pm 1.6$ and $6.51 \pm 0.7$, respectively. In conclusion, the bioactivity of gooseberry was lower than blueberries and cranberries. The antioxidant and binding properties of gooseberries in comparison with widely consumed blueberries and cranberries can be used as a new source for food supplementation.

Keywords Berries - Bioactive compounds - Antioxidant activity $\cdot$ Binding properties

\section{Introduction}

Berries contain powerful antioxidants, potential allergens, and other bioactive compounds. Genetic and environmental factors affect production and storage of such compounds, where the anthocyanins (water-soluble plant pigments) have important functions in plant physiology as well in health effects [1]. The high anthocyanin contents and biological activities of these fruits indicate that their consumption would be beneficial to health. It was revealed that the fruits contained superior levels of anthocyanins (146-2,199 mg/100 g fresh weight) to those previously reported for other raspberry and blackberry species, and their hexane, EtOAc, and $\mathrm{MeOH}$ extracts showed good antioxidant activity. The majority of the extracts exhibited 
over $50 \%$ lipid peroxidation inhibitory activity at $50 \mathrm{mg} /$ $\mathrm{mL}$. This may be useful in the production of functional foods containing an efficacious dose of anthocyanins [2]. The presence of predominantly phenolic compounds (ellagic and gallic acids, and corilagin) demonstrated varying degrees of antioxidative efficacy [3]. Cranberries with high content of polyphenols have been associated with several cardiovascular health benefits [4]. Borges et al. [5] identified the content of bioactive compounds in different berries. A complex spectrum of anthocyanins was the major contributor to the TAC of blueberries, whereas the lower TAC of cranberries was due mainly to reduced anthocyanin content. Vitamin $\mathrm{C}$ was responsible for 18-23\% of the TAC of cranberries and did not contribute to the TAC of the blueberry extract [5]. Puente et al. [6] studied the physicochemical and nutritional properties of the Physalis peruviana L. fruit and their relation of active components with beneficial effects on human health. The food industry has used cape gooseberry in different products including beverages, yogurts and jams, nutraceutical, and pharmaceutical industries [7, 8]. All the evaluated gooseberries extracts presented detectable amounts of phenolic, flavonoid, and tannin. Different extraction procedures reported in the literature and used to extract antioxidants in fruit were compared and analyzed [9, 10]. In our recent research, polyphenols, flavonoids, flavanols, and tannins and the level of antioxidant activity by ABTS, FRAP, and CUPRAC radical scavenging assays of methanol extract of studied berry samples were determined and compared. It was found that the contents of the polyphenol compounds and the level of antioxidant activity in extracts of berries differ significantly [11]. We were interested to investigate extracts of gooseberry (Physalis peruviana) and to compare its composition with the widely consumed berries. The water extracts of berries are important from the point of tea consumption all year around, outside of the season of growing. To meet this aim, the contents of bioactive compounds (polyphenols, tannins, anthocyanins, and ascorbic acid) and the levels of total antioxidant capacities (TAC) were determined and compared. Two radical scavenging assays ABTS and FRAP were carried out in order to determine the TAC $[12,13]$. Human serum albumin is the drug carrier's protein and serves to greatly amplify the capacity of plasma for transporting drugs. In order to compare the fluorescence properties of the extracted bioactive compounds, in vitro studies were performed by interaction of proteins with polyphenols. It is interesting to investigate in vitro how this protein interacts with polyphenols extracted from berry samples in order to get useful information of the properties of polyphenol-protein complex. Different aspects of berries phenolics activity were studied in individual papers [7-10, 14], but complex study in this matter is missing. Therefore, the aim of this study was to determine the antioxidant and binding properties of the water extracts of gooseberry in comparison with blueberry and cranberry on the basis of interaction with HSA. As far as we know, no results of such investigations were published.

\section{Materials and methods}

\section{Reagents}

6-Hydroxy-2,5,7,8-tetramethylchroman-2-carboxylic acid (Trolox), caffeic acid, 2,2-azino-bis (3-ethylbenzthiazoline-6-sulfonic acid) (ABTS), Folin-Ciocalteu reagent (FCR), lanthanum (III) chloride heptahydrate; $\mathrm{CuCl}_{2} \times$ $2 \mathrm{H}_{2} \mathrm{O}$; and 2,9-dimethyl-1,10-phenanthroline (neocuproine) $\mathrm{FeCl}_{3} \times 6 \mathrm{H}_{2} \mathrm{O}$ were purchased from Sigma Chemical Co., St Louis, MO, USA. 2, 4, 6-Tripyridyl-s-triazine (TPTZ) was from Fluka Chemie, Buchs, Switzerland. All reagents were of analytical grade. Deionised and distilled water was used throughout.

\section{Samples}

Cape gooseberries (Physalis peruviana), blueberries (Vaccinium corymbosum), and cranberries (Vaccinium macrocarpon) were investigated. All berries were purchased at the local market in Gdansk and Warsaw, Poland. For the investigation, five replicates of five berries each were used. Their edible parts were prepared manually without using steel knives. The prepared berries were weighed, chopped, and homogenized under liquid nitrogen in a high-speed blender (Hamilton Beach Silex professional model) for $1 \mathrm{~min}$. A weighed portion (50-100 g) was then lyophilized for $48 \mathrm{~h}$ (Virtis model 10-324), and the dry weight was determined. The samples were ground to pass through a $0.5 \mathrm{~mm}$ sieve and stored at $-20^{\circ} \mathrm{C}$ until the bioactive substances were analyzed.

Determination of bioactive compounds and total antioxidant capacity (TAC)

The contents of polyphenols, tannins, anthocyanins, and ascorbic acid in extracts of the studied berries were determined as previously described [15]. The lyophilized samples of berries $(1 \mathrm{~g})$ were extracted with $100 \mathrm{~mL}$ of methanol/water $(1: 1)$ at room temperature and in darkness for $24 \mathrm{~h}$. The extracts were filtered in a Buchner funnel. After removal of the methanol in a rotary evaporator at a temperature below $40{ }^{\circ} \mathrm{C}$, the aqueous solution was extracted with diethyl ether and ethyl acetate, and then, the remainder of the aqueous solution was freeze-dried. The organic fractions were dried and redissolved in methanol. 
These extracts were used for MS, for determination of bioactive compounds [16].

The polyphenols were determined by Folin-Ciocalteu method with measurement at $750 \mathrm{~nm}$ with spectrophotometer (Hewlett-Packard, model 8452A, Rockvile, USA). The results were expressed as $\mathrm{mg}$ of gallic acid equivalents (GAE) per g DW [17]. The extracts of condensed tannins (procyanidins) with $4 \%$ methanol vanillin solution were measured at $500 \mathrm{~nm}$. (+)-Catechin served as a standard for flavonoids, and the results were expressed as catechin equivalents (CE). Total ascorbic acid was determined by CUPRAC assay [18] in water extract (100 mg of lyophilized sample and $5 \mathrm{ml}$ of water). The absorbance of the formed bis (Nc)-copper (I) chelate was measured at $450 \mathrm{~nm}$. The total anthocyanins were measured by a $\mathrm{pH}$ differential method. Absorbance was measured in a Beckman spectrophotometer at $510 \mathrm{~nm}$ and at $700 \mathrm{~nm}$ in buffers at $\mathrm{pH} 1.0$ and 4.5 , using $A=\left[\left(\mathrm{A}_{510}-\mathrm{A}_{700}\right)_{\mathrm{pH} 1.0^{-}}\right.$ $\left.\left(\mathrm{A}_{510}-\mathrm{A}_{700}\right)_{\mathrm{pH} 4.5}\right]$. Results were expressed as $\mathrm{mg}$ of cyanidin-3-glucoside equivalent (CGE)/g of DW [19].

MS analysis: A mass spectrometer, a TSQ Quantum Access Max (Thermo Fisher Scientific, Basel, Switzerland), was used. Analytes were ionized by electrospray ionization (ESI) in positive mode. Vaporizer temperature was kept at $100{ }^{\circ} \mathrm{C}$. Settings for the ion source were as follows: spray voltage $3,000 \mathrm{~V}$, sheath gas pressure $35 \mathrm{AU}$; ion sweep gas pressure $0 \mathrm{AU}$; auxiliary gas pressure at 30 $\mathrm{AU}$; capillary temperature at $200{ }^{\circ} \mathrm{C}$; skimmer offset $0 \mathrm{~V}$ [20].

The TAC was determined by two assays:

1. 2, 2-Azino-bis (3-ethyl-benzothiazoline-6-sulfonic acid) diammonium salt $\left(\mathrm{ABTS}^{+}\right)$method for the screening of antioxidant activity is reported as a decolorization assay applicable to both lipophilic and hydrophilic antioxidants, including flavonoids, hydroxycinnamates, carotenoids, and plasma antioxidants. The influences of both the concentration of antioxidant and duration of reaction on the inhibition of the radical cation absorption are taken into account when determining the antioxidant capacity. $\mathrm{ABTS}^{+}$ radical cation was generated by the interaction of ABTS $(7 \mathrm{mM} / \mathrm{L})$ and $\mathrm{K}_{2} \mathrm{~S}_{2} \mathrm{O}_{8}(2.45 \mathrm{mM} / \mathrm{L})$. This solution was diluted with methanol until the absorbance in the samples reached 0.7 at $734 \mathrm{~nm}$ [13].

2. Ferric-reducing/antioxidant power (FRAP) assay measures the ability of the antioxidants in the investigated samples to reduce ferric-tripiridyltriazine $\left(\mathrm{Fe}^{3+}\right.$-TPTZ) to a ferrous form $\left(\mathrm{Fe}^{2}\right)$. FRAP reagent $(2.5 \mathrm{~mL}$ of a $10 \mathrm{mmol}$ ferric-tripiridyltriazine solution in $40 \mathrm{mmol}$ $\mathrm{HCl}$ plus $2.5 \mathrm{~mL}$ of $20 \mathrm{mmol} \mathrm{FeCl}_{3} \mathrm{xH}_{2} \mathrm{O}$ and $25 \mathrm{~mL}$ of $0.3 \mathrm{~mol} / \mathrm{L}$ acetate buffer, $\mathrm{pH} 3.6$ ) of $900 \mu \mathrm{L}$ was mixed with $90 \mu \mathrm{L}$ of distilled water and $30 \mu \mathrm{L}$ of berry samples as the appropriate reagent blank. The absorbance was measured at $595 \mathrm{~nm}$ [12].

Fluorometry and Fourier transform infrared (FT-IR) spectra studies

Two-dimensional (2D-FL) fluorescence measurements for all berries extracts at a concentration of $0.01 \mathrm{mg} / \mathrm{mL}$ were recorded on a model FP-6500, Jasco spectrofluorometer, serial N261332, Japan, equipped with $1.0 \mathrm{~cm}$ quartz cells and a thermostat bath. The 2D-FL was taken at emission wavelengths from 310 to $500 \mathrm{~nm}$, and at excitation of $295 \mathrm{~nm}$ [11]. Caffeic acid was used as a standard. All solutions for protein interaction were prepared in 0.05 $\mathrm{mol} / \mathrm{L}$ Tris-HCl buffer $(\mathrm{pH} 7.4$ ), containing $0.1 \mathrm{~mol} / \mathrm{L}$ $\mathrm{NaCl}$. The final concentration of HSA was $2.0 \times 10^{-6} \mathrm{~mol} / \mathrm{L}$. The HSA was mixed with caffeic acid in the proportions of HSA: extract $=1: 1[14,21,22]$. The presence of polyphenols in the investigated berries samples was studied by Fourier transform infrared (FT-IR) spectroscopy. A Nicolet iS 10 FT-IR Spectrometer (Thermo Scientific Instruments LLC, Madison, WI, USA), with the smart $\mathrm{iTR}^{\mathrm{TM}}$ ATR (Attenuated Total Reflectance) accessory, was used to record IR spectra [23].

Statistical analyses

To verify the statistical significance, mean \pm SD of five independent measurements were calculated. Differences between groups were tested by two-ways ANOVA. In the assessment of the antioxidant capacity, Spearman correlation coefficients $(R)$ were used. Linear regressions were also calculated. $P$-values of $<0.05$ were considered significant.

\section{Results}

Bioactive compounds

The amounts of bioactive compounds in all studied samples are summarized in Table 1 and Fig. 1. As can be seen, the significant highest content $(P<0.05)$ of bioactive compounds was in blueberries water extract. Gooseberries showed average results in water extracts for polyphenols, tannins, anthocyanins, and ascorbic acid (Table 1, Fig. 1).

Total antioxidant capacity (TAC)

The results of the determination of the level of TAC of all studied samples are shown in Table 1. As can be seen, the TAC $(\mu \mathrm{MTE} / \mathrm{g})$ by ABTS and FRAP assays for 
Table 1 Bioactive compounds and antioxidant capacities in water, ethyl acetate, and diethyl ether extracts of gooseberries (Physalis peruviana), cranberries (Vaccinium macrocarpon), and blueberries (Vaccinium corymbosum)

\begin{tabular}{|c|c|c|c|c|}
\hline \multirow[t]{2}{*}{ Extracts } & \multicolumn{4}{|l|}{ Indices } \\
\hline & POLYPHEN, mg GAE & TANNINS, mg CE & ABTS, $\mu \mathrm{M}$ TE & FRAP, $\mu \mathrm{M}$ TE \\
\hline Goberry, $\mathrm{H}_{2} \mathrm{O}$ & $5.37 \pm 0.6^{\mathrm{c}}$ & $0.71 \pm 0.2^{\mathrm{c}}$ & $15.53 \pm 1.6^{\mathrm{c}}$ & $6.51 \pm 0.7^{\mathrm{c}}$ \\
\hline Crberry, $\mathrm{H}_{2} \mathrm{O}$ & $22.13 \pm 2.5^{\mathrm{b}}$ & $5.12 \pm 0.7^{\mathrm{b}}$ & $72.76 \pm 6.5^{\mathrm{b}}$ & $26.97 \pm 2.7^{\mathrm{b}}$ \\
\hline Blberry, $\mathrm{H}_{2} \mathrm{O}$ & $46.56 \pm 4.2^{\mathrm{a}}$ & $13.04 \pm 1.3^{\mathrm{a}}$ & $199.41 \pm 18.6^{\mathrm{a}}$ & $94.10 \pm 9.3^{\mathrm{a}}$ \\
\hline Goberry, EtOAc & $0.29 \pm 0.1^{\mathrm{e}}$ & $0.31 \pm 0.1^{\mathrm{d}}$ & $1.47 \pm 0.3^{\mathrm{e}}$ & $0.42 \pm 0.1^{\mathrm{d}}$ \\
\hline Crberry, EtOAc & $3.14 \pm 0.4^{\mathrm{c}}$ & $0.51 \pm 0.1^{\mathrm{c}}$ & $13.50 \pm 1.3^{\mathrm{c}}$ & $5.10 \pm 0.6^{\mathrm{c}}$ \\
\hline Blberry, EtOAc & $3.87 \pm 0.4^{\mathrm{c}}$ & $0.62 \pm 0.2^{\mathrm{c}}$ & $17.73 \pm 1.8^{\mathrm{c}}$ & $7.53 \pm 0.8^{\mathrm{c}}$ \\
\hline Goberry, DEE & $0.14 \pm 0.01^{\mathrm{e}}$ & $0.30 \pm 0.1^{\mathrm{d}}$ & $0.88 \pm 0.1^{\mathrm{e}}$ & $0.084 \pm 0.01^{\mathrm{e}}$ \\
\hline Crberry, DEE & $2.11 \pm 0.2^{\mathrm{d}}$ & $0.32 \pm 0.1^{\mathrm{d}}$ & $10.72 \pm 1.8^{\mathrm{d}}$ & $3.28 \pm 0.4^{\mathrm{d}}$ \\
\hline Blberry, DEE & $4.13 \pm 0.4^{\mathrm{c}}$ & $0.62 \pm 0.3^{\mathrm{c}}$ & $20.42 \pm 2.3^{\mathrm{c}}$ & $9.59 \pm 0.9^{\mathrm{c}}$ \\
\hline
\end{tabular}

Values are mean \pm SD of 5 measurements

Per g dry weight

Values in columns for every bioactive compound bearing different superscript letters are significantly different $(P<0.05)$

POLYPHEN polyphenols, $C E$ catechin equivalent, GAE gallic acid equivalent, ABTS 2, 2-Azino-bis (3-ethyl-benzothiazoline-6-sulfonic acid) diammonium salt, FRAP Ferric-reducing/antioxidant power, Goberry gooseberries (Physalis peruviana), Crberry cranberries (Vaccinium macrocarpon), Blberry blueberries (Vaccinium corymbosum), EtOAc ethyl acetate, DEE diethyl ether

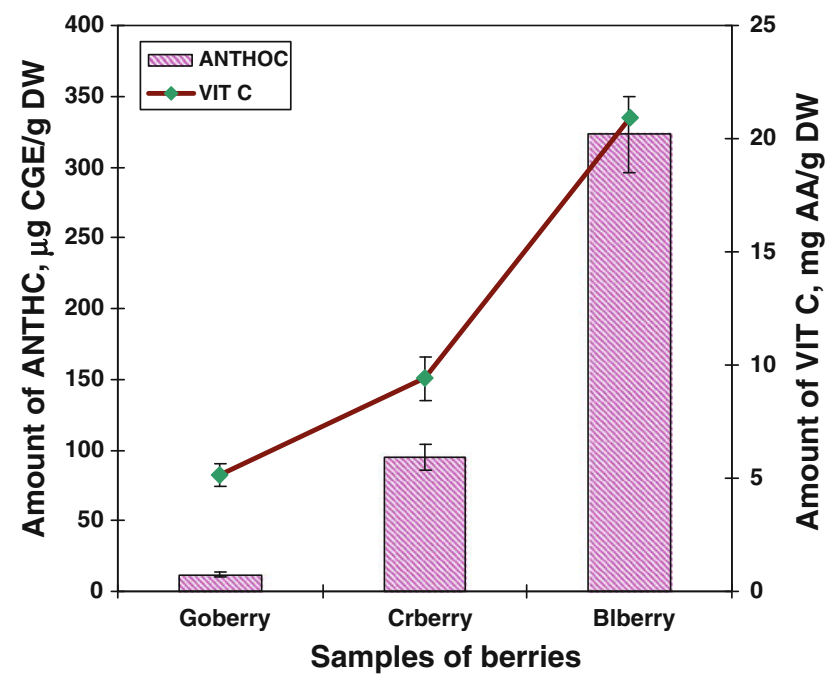

Fig. 1 Total anthocyanins ( $\mu \mathrm{g}$ CGE/g DW) and vitamin C (mg AA/g $\mathrm{DW})$ in gooseberries, blueberries and cranberries. $C G E$ cyanidin-3glucoside equivalent, $A A$ ascorbic acid, Goberry gooseberries, Crberry cranberries, Blberry blueberries, ANTHOC anthocyanins, VIT C, vitamin C

gooseberries was $15.53 \pm 1.6$ and $6.51 \pm 0.7$, respectively. The TAC of blueberries was higher than that of gooseberries and cranberries. A very good correlation was found between the TAC and the contents of total polyphenols $\left(R^{2}\right.$ from 0.96 to 0.83$)$ in water extracts. The correlation between the antioxidant capacity and ascorbic acid (Fig. 1) was lower than with polyphenols $\left(R^{2}\right.$ from 0.84 to 0.50 , Table 1$)$.

\section{Mass spectra data}

The spectrum shows the main $\mathrm{m} / \mathrm{z}$ peaks found (Fig. 2a, b, c) in water extract of berries with relative abundance (RA \%) from 5 to $100 \%$. The main peaks were about 393, 381, and 290 for cranberries, gooseberries, and blueberries, respectively [20]. Other peaks appeared for cranberry at $335(87 \%)$, for blueberries at $241(70 \%)$, for cranberry and blueberry were found at 104 with RA $=40 \%$, and $\mathrm{RA}=66 \%$. Common peaks at 266 of $50 \%$ and $32 \%$ were in gooseberries and cranberries, respectively. The peaks of 116 (45\%), of 146 (25\%), and 219 (32\%) were estimated only in gooseberries. The RA of the obtained peaks corresponded with the amount of total polyphenols contents in these samples.

Fluorometry spectra studies and FTIR

Water extracts showed the highest antioxidant properties; therefore, only water extracts were subjected to binding studies with HSA. The scavenging properties of the berries samples in comparison with caffeic acid are shown in twodimensional fluorescence spectra (2D-FL). One of the main peaks for HSA was found at $\lambda$ ex/em of $220 / 360 \mathrm{~nm}$. The second main peak appeared for these samples at $\lambda \mathrm{ex} /$ em of 280/350 nm (Fig. 3b-d). The interaction of HSA and the water extracts of berries, HSA, water extracts and caffeic acid (Fig. 3b-d) showed slight change in the position of the main peak at the wavelength of $360 \mathrm{~nm}$ and the decrease in the relative fluorescence intensity (RFI). The 

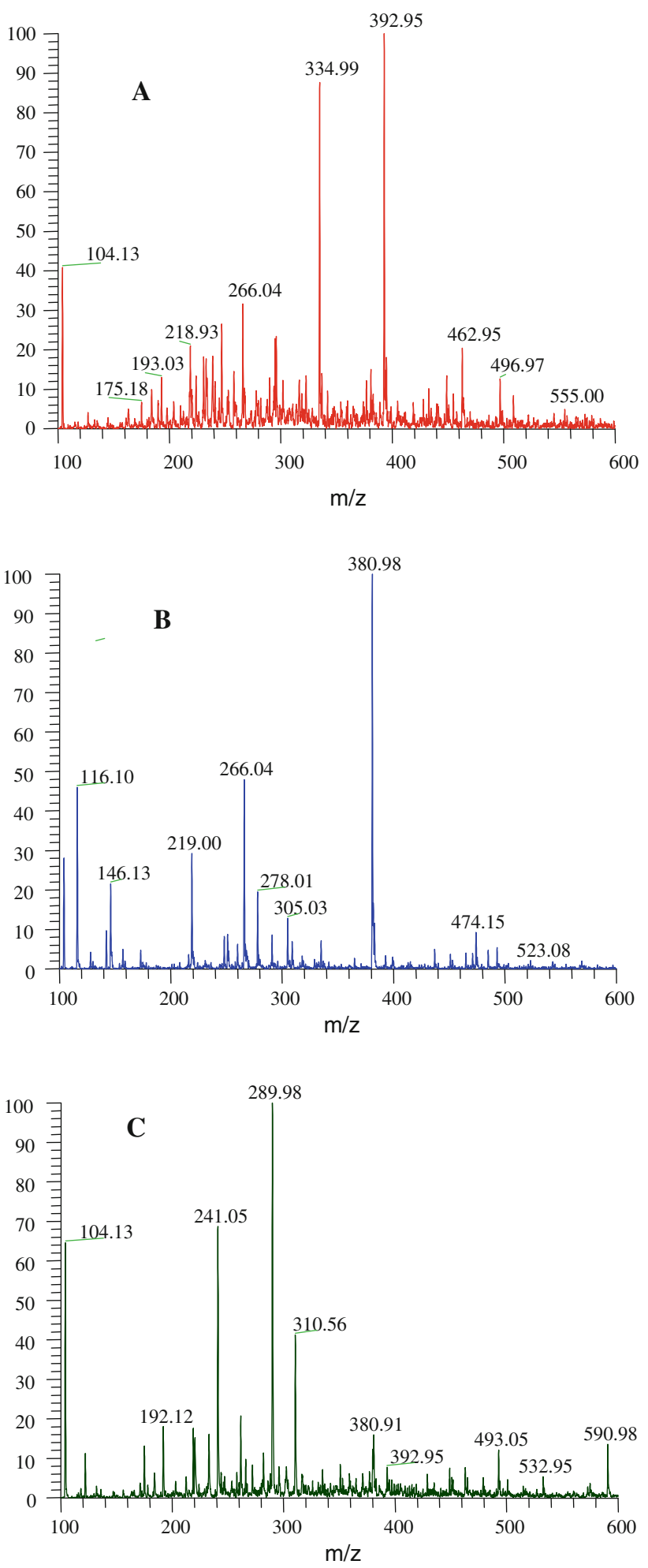

Fig. 2 ESI-MS spectra in positive ion mode of water fractions of the following berries: a cranberries; b gooseberries; c blueberries

following changes appeared when the water extracts of berries were added to HSA [initially the main peak at emission $360 \mathrm{~nm}$ and FI of 904.26 (Figs. 3a, b, and 4a, the upper line is HSA). The addition of blueberry extracts and caffeic acid decreased the RFI of HSA (Fig. 3b, lines from the top to the bottom). The decrease in the RFI (\%) was proportional to the concentration of the polyphenols and showed 23.3, 58.3, and 67.5 during interaction of 20, 100, and $200 \mu \mathrm{g} / \mathrm{mL}$ blueberry water extract with HSA. Oppositely, in the case of addition of caffeic acid, the decrease was of 29.0, 71.1, and $73 \%$, respectively. Cranberry extracts showed the following results (Fig. 3c): HSA with $20 \mu \mathrm{g} / \mathrm{mL}$ decreased the RFI on $12.5 \%$ and $\mathrm{CaA}-23.1 \%$; with $100 \mu \mathrm{g} / \mathrm{mL} 28.5 \%$ and $\mathrm{CaA}-42.4 \%$; and with $200 \mu \mathrm{g} / \mathrm{mL}$ of extract decreased the RFI on $35.9 \%$ and with $\mathrm{CaA}$ on $47.7 \%$. Gooseberry extracts showed decrease in fluorescence (Fig. 3d): with $20 \mu \mathrm{g} / \mathrm{mL}$ on $3.1 \%$ and addition of $\mathrm{CaA}-16.2 \%$; with $100 \mu \mathrm{g} / \mathrm{mL}$ on $10.8 \%$ and $22.0 \%$, respectively; and with $200 \mu \mathrm{g} / \mathrm{mL}$ on $16.5 \%$ and with $\mathrm{CaA}-27.6 \%$. The decrease in the RFI of HSA with $200 \mu \mathrm{g} / \mathrm{mL}$ gooseberry, cranberry, and blueberry extracts was $16.5,35.9$, and $67.5 \%$, and when caffeic acid was added, the decrease was $27.6,47.7$, and $73 \%$, respectively (Fig 3b-d).

FTIR spectra of water extracts of gooseberries, blueberries, and cranberries (A), ethyl acetate extracts of blueberries, gooseberries, and cranberries (B), and diethyl ether extracts (C) of gooseberries, blueberries, and cranberries are presented in Fig. 4 (lines from the top to the bottom). The comparison between the berries, the extracts, and some standards in the range of common peaks is shown in Table $2 \mathrm{~A}, \mathrm{~B}, \mathrm{C}$. The best matching in the common range of the peaks was in water extracts of the berries samples in the range of $3,300-3,000 \mathrm{~cm}^{-1}$ (Table $2 \mathrm{~A}$ ) of $75 \%$ with hesperidin and $85 \%$ with tannic acid. Caffeic acid showed the matching in the range of 2,500-2,000 $\mathrm{cm}^{-1}$ (Table $2 \mathrm{~A}$ ) of $42 \%$. In ethyl acetate extract, similar matching in the range of 3,500-3,200 $\mathrm{cm}^{-1}$ of the peaks was found with tannic acid and quercetin (Table $2 \mathrm{~B}$ ). In the range of $2,400-2,300 \mathrm{~cm}^{-1}$ (Table 2 B), gallic acid, fisetin, tannic, and caffeic acids showed about $70-78 \%$ of common peaks.

\section{Discussion}

It was of great interest to compare gooseberries in order to find out if their bioactivity is on the same level as in other widely consumed berries and to use this kind of berries as a daily diet supplement. Therefore, the contents of the bioactive compounds and TAC were determined and compared with the widely consumed blueberries and cranberries. As it was declared in Results, the contents of bioactive compounds (polyphenols, tannins, anthocyanins, and ascorbic acid) in three extracts were determined and compared. The significantly highest amounts of bioactive compounds were 

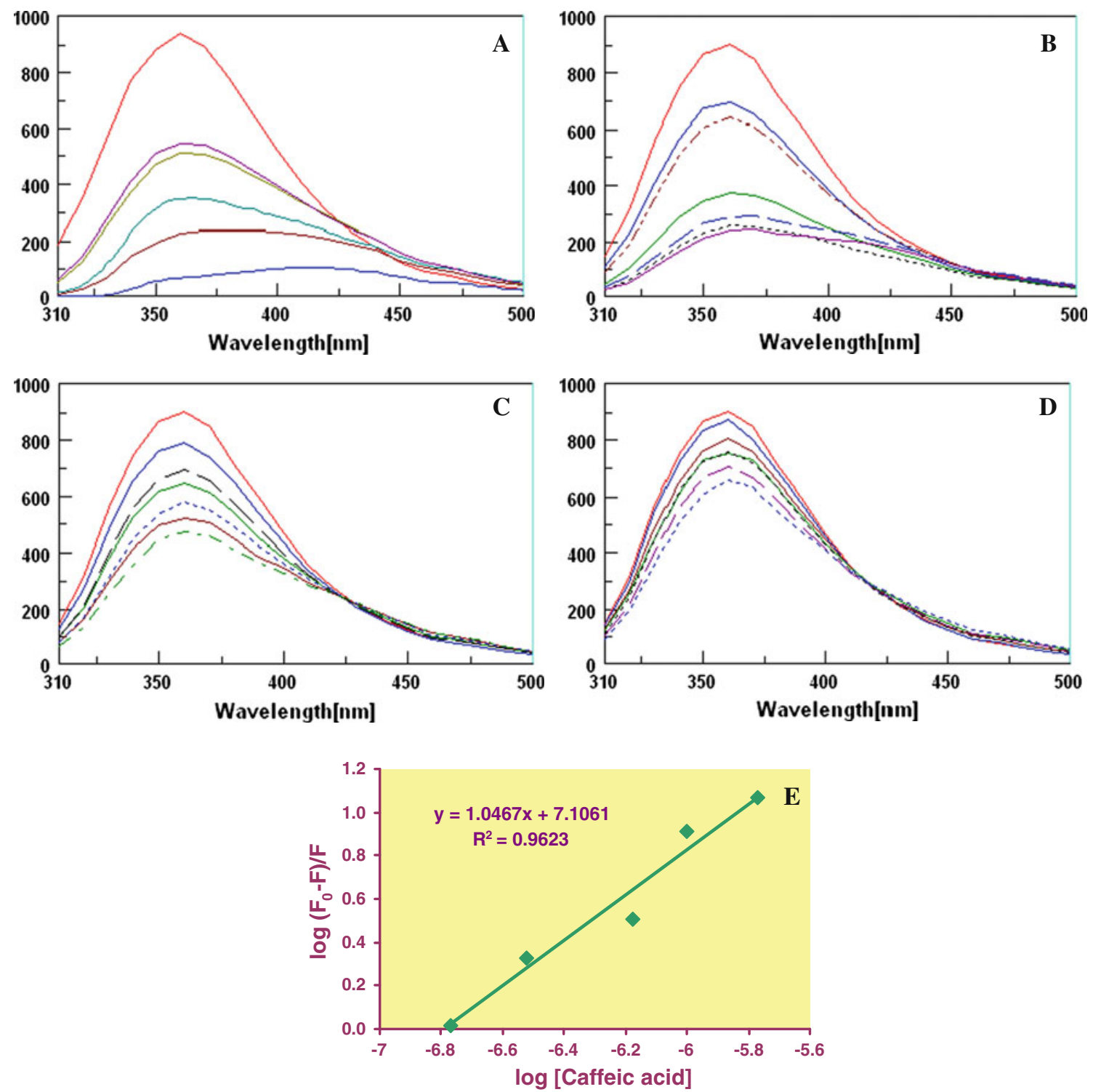

Fig. 3 Change in the relative fluorescence intensity (RFI) in twodimensional fluorescence (2D-FL) spectra as a result of binding affinity of HSA, caffeic acid (CaA, $\left.0.79 \times 10^{-6} \mathrm{~mol} / \mathrm{L}\right)$, and water extracts of berries: a fluorescence spectra of water extract of HSA $\left(2.0 \times 10^{-6} \mathrm{~mol} / \mathrm{L}\right)$ in the presence of different concentrations of $\mathrm{CaA} 0,0.17,0.30,0.67,1.0$, and $1.7 \times\left(10^{-6}\right) \mathrm{mol} / \mathrm{L}$ at $\mathrm{pH} 7.4$ at excitation wavelength of $290 \mathrm{~nm}$ (lines from the top to the bottom with RFI of 947.37, 545.49, 509.67, 352.50, 237.02, 107.70). b Lines from the top to the bottom with RFI of 904.26, 693.69, 640.57, $376.89,294.08,261.65$, and 244.51 of HSA, HSA and $20 \mu \mathrm{g} / \mathrm{mL}$ Blberry, HSA and $20 \mu \mathrm{g} / \mathrm{mL}$ Blberry and CaA, HSA and $100 \mu \mathrm{g} / \mathrm{mL}$ Blberry, HSA and $200 \mu \mathrm{g} / \mathrm{mL}$ Blberry, HSA and $100 \mu \mathrm{g} / \mathrm{mL}$ Blberry and $\mathrm{CaA}$, HSA and $200 \mu \mathrm{g} / \mathrm{mL}$ Blberry and CaA. c Lines from the top to the bottom with RFI of 904.26, 791.65, 695.64, 646.56, 579.72,

in water extract of all investigated berries, and the highest between the investigated berries was in blueberries. Also, the TAC according to ABTS and FRAP was significantly higher in water extract of blueberries. Our results correspond also with the data of $\mathrm{Wu}$ et al. [1], where concentrations of total
520.84, and 472.82 for HSA; HSA and $20 \mu \mathrm{g} / \mathrm{mL}$ Crberry, HSA and $20 \mu \mathrm{g} / \mathrm{mL}$ Crberry, and CaA, HSA and $100 \mu \mathrm{g} / \mathrm{mL}$ Crberry, HSA and $200 \mu \mathrm{g} / \mathrm{mL}$ Crberry, HSA and $100 \mu \mathrm{g} / \mathrm{mL}$ Crberry and CaA, HSA and $200 \mu \mathrm{g} / \mathrm{mL}$ Crberry and CaA. d Lines from the top to the bottom with RFI of $904.26,876.48,806.60,757.74,755.29,705.17$, and 654.84 for HSA, HSA and $20 \mu \mathrm{g} / \mathrm{mL}$ Goberry, HSA and $100 \mu \mathrm{g} / \mathrm{mL}$ Goberry, HSA and $20 \mu \mathrm{g} / \mathrm{mL}$ Goberry and CaA, HSA and $200 \mu \mathrm{g} / \mathrm{mL}$ Goberry; HSA and $100 \mu \mathrm{g} / \mathrm{mL}$ Goberry and CaA, HSA and $200 \mu \mathrm{g} / \mathrm{mL}$ Goberry and CaA. e The linear plot for $\log \left(\mathrm{F}_{0}-\mathrm{F}\right) / \mathrm{F}$ versus $\log$ [caffeic acid], where $\mathrm{F}_{0}$, and $\mathrm{F}$ represent the fluorescence intensity of HSA in the absence and in the presence of caffeic acid. Abbreviations: HSA, human serum albumin; Go, gooseberry, Crberry, cranberry and Blberry, blueberry

anthocyanins varied considerably from 0.7 to $1,480 \mathrm{mg} /$ 100 g FW in gooseberry ('Careless' variety) and chokeberry, respectively. Total phenolic content and total anthocyanin content of four berry fruits (strawberry, Saskatoon berry, raspberry and wild blueberry), chokecherry, and 

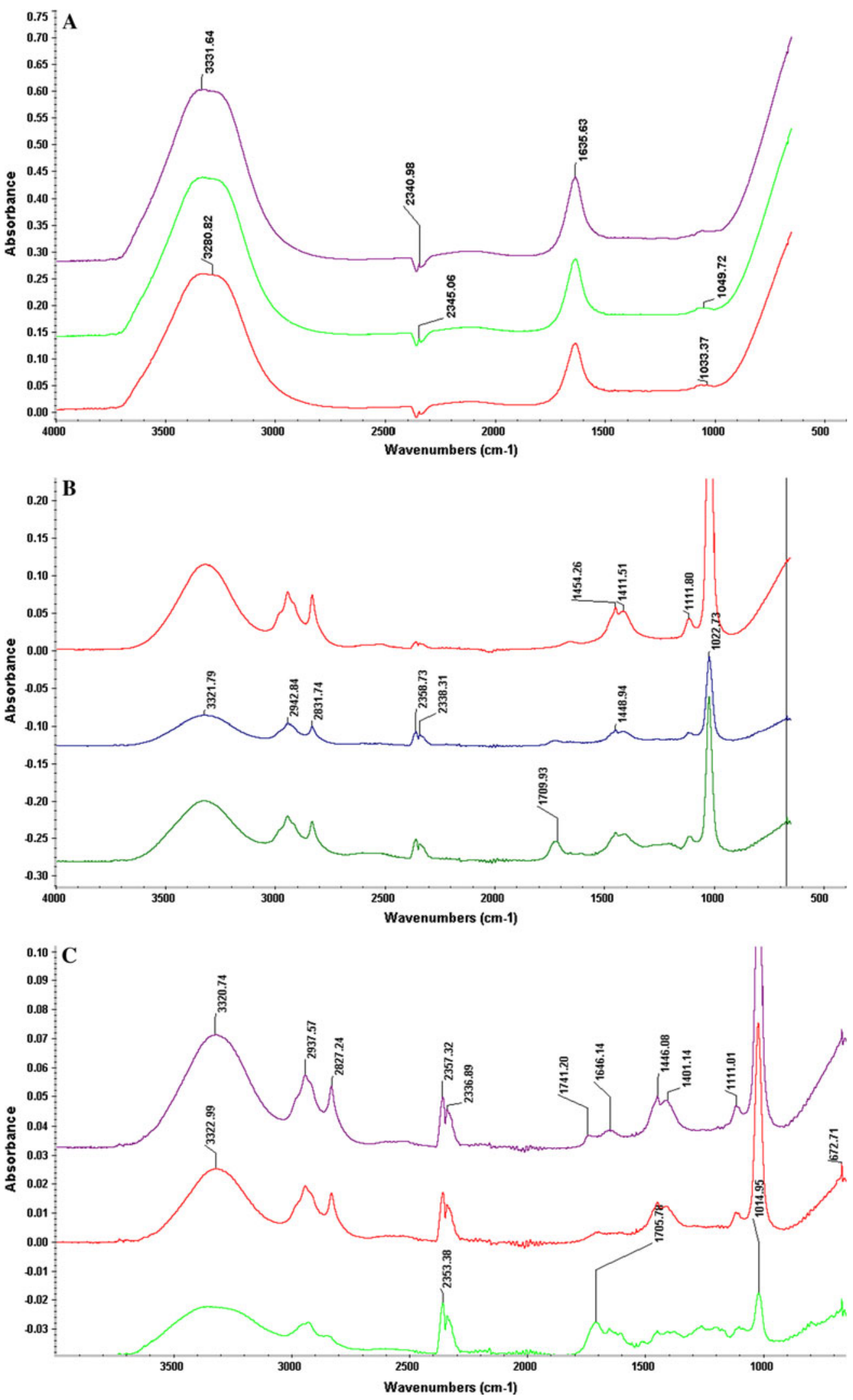

Fig. 4 FTIR spectra of: a water extracts of gooseberries, blueberries, and cranberries from the top to the bottom. b ethyl acetate extracts of blueberries, gooseberries, and cranberries from the top to the bottom. c diethyl ether extracts of gooseberries, blueberries, and cranberries from the top to the bottom 
Table 2 Matching of the peaks (\%) in the FTIR spectra of polyphenols and standards in water (A), ethyl acetate (B) and diethyl ether (C) extracts from

\begin{tabular}{|c|c|c|c|c|c|c|c|c|c|c|c|c|}
\hline \multirow{3}{*}{$\begin{array}{l}\text { Range of bands } \\
\text { Standards }\end{array}$} & \multicolumn{3}{|c|}{$3,300-3,000 \mathrm{~cm}^{-1}$} & \multicolumn{3}{|c|}{$2,500-2,000 \mathrm{~cm}^{-1}$} & \multicolumn{3}{|c|}{$1,800-1,500 \mathrm{~cm}^{-1}$} & \multicolumn{3}{|c|}{$1,200-900 \mathrm{~cm}^{-1}$} \\
\hline & \multicolumn{12}{|c|}{ Matching of standards/samples (\%) } \\
\hline & Gob & Blb & $\mathrm{Crb}$ & Gob & Blb & $\mathrm{Crb}$ & Gob & $\mathrm{Blb}$ & $\mathrm{Crb}$ & Gob & Blb & $\mathrm{Crb}$ \\
\hline \multicolumn{13}{|l|}{ A } \\
\hline Gallic acid & 42 & 44 & 42 & 37 & 38 & 38 & 0 & 1 & 1 & 23 & 18 & 20 \\
\hline Ferulic acid & 21 & 22 & 22 & 26 & 28 & 28 & 2 & 2 & 2 & 2 & 0 & 0 \\
\hline Fisetin & 20 & 20 & 25 & 35 & 37 & 37 & 4 & 4 & 4 & 6 & 6 & 6 \\
\hline Hesperedin & 75 & 75 & 75 & 5 & 7 & 7 & 29 & 29 & 29 & 19 & 15 & 15 \\
\hline Tannic acid & 85 & 85 & 85 & 41 & 44 & 44 & 6 & 6 & 6 & 17 & 12 & 12 \\
\hline Caffeic acid & 26 & 26 & 25 & 41 & 42 & 42 & 26 & 26 & 26 & 8 & 3 & 7 \\
\hline Quercetin & 73 & 73 & 73 & 18 & 19 & 19 & 4 & 4 & 4 & 7 & 5 & 5 \\
\hline \multirow{3}{*}{$\begin{array}{l}\text { Range of bands } \\
\text { Standards }\end{array}$} & \multicolumn{3}{|c|}{$3,500-3,200 \mathrm{~cm}^{-1}$} & \multicolumn{3}{|c|}{$3,000-2,800 \mathrm{~cm}^{-1}$} & \multicolumn{3}{|c|}{$2,400-2,300 \mathrm{~cm}^{-1}$} & \multicolumn{3}{|c|}{$1,800-900 \mathrm{~cm}^{-1}$} \\
\hline & \multicolumn{12}{|c|}{ Matching of standards/samples (\%) } \\
\hline & Gob & Blb & $\mathrm{Crb}$ & Gob & Blb & $\mathrm{Crb}$ & Gob & Blb & Crb & Gob & Blb & $\mathrm{Crb}$ \\
\hline \multicolumn{13}{|l|}{ B } \\
\hline Gallic acid & 48 & 51 & 46 & 8 & 9 & 11 & 75 & 73 & 72 & 45 & 46 & 43 \\
\hline Ferulic acid & 22 & 19 & 22 & 15 & 15 & 16 & 57 & 55 & 57 & 15 & 13 & 19 \\
\hline Fisetin & 17 & 26 & 16 & 10 & 11 & 15 & 71 & 70 & 70 & 17 & 13 & 8 \\
\hline Hesperedin & 57 & 55 & 61 & 28 & 23 & 24 & 1 & 1 & 0 & 5 & 4 & 5 \\
\hline Tannic acid & 79 & 77 & 78 & 13 & 13 & 15 & 77 & 77 & 78 & 51 & 48 & 57 \\
\hline Caffeic acid & 18 & 15 & 17 & 36 & 39 & 39 & 77 & 75 & 76 & 12 & 16 & 10 \\
\hline Quercetin & 73 & 72 & 71 & 0 & 6 & 9 & 36 & 34 & 36 & 4 & 6 & 9 \\
\hline \multirow{3}{*}{$\begin{array}{l}\text { Range of bands } \\
\text { Standards }\end{array}$} & \multicolumn{3}{|c|}{$3,300-3,100 \mathrm{~cm}^{-1}$} & \multicolumn{3}{|c|}{$3,000-2,800 \mathrm{~cm}^{-1}$} & \multicolumn{3}{|c|}{$2,500-2,200 \mathrm{~cm}^{-1}$} & \multicolumn{3}{|c|}{$1,800-600 \mathrm{~cm}^{-1}$} \\
\hline & \multicolumn{12}{|c|}{ Matching of standards/samples (\%) } \\
\hline & Gob & $\mathrm{Blb}$ & $\mathrm{Crb}$ & Gob & $\mathrm{Blb}$ & $\mathrm{Crb}$ & Gob & $\mathrm{Blb}$ & $\mathrm{Crb}$ & Gob & Blb & $\mathrm{Crb}$ \\
\hline \multicolumn{13}{|l|}{$\mathrm{C}$} \\
\hline Gallic acid & 50 & 47 & 48 & 12 & 10 & 26 & 61 & 59 & 61 & 30 & 29 & 22 \\
\hline Ferulic acid & 15 & 9 & 31 & 15 & 16 & 4 & 38 & 37 & 37 & 6 & 37 & 9 \\
\hline Fisetin & 25 & 25 & 22 & 9 & 9 & 4 & 51 & 49 & 51 & 3 & 2 & 3 \\
\hline Hesperedin & 90 & 87 & 73 & 30 & 27 & 31 & 5 & 5 & 5 & 4 & 4 & 6 \\
\hline Tannic acid & 85 & 78 & 75 & 16 & 14 & 27 & 67 & 66 & 67 & 41 & 42 & 32 \\
\hline Caffeic acid & 8 & 3 & 21 & 36 & 37 & 9 & 58 & 58 & 58 & 2 & 3 & 9 \\
\hline Quercetin & 69 & 65 & 59 & 3 & 3 & 4 & 29 & 28 & 29 & 3 & 1 & 12 \\
\hline
\end{tabular}

Gob gooseberries, Blb blueberries, Crb cranberries

seabuckthorn ranged from 22.83 to $131.88 \mathrm{~g} / \mathrm{kg}$ and 3.51 to $13.13 \mathrm{~g} / \mathrm{kg}$, respectively, which corresponds with our results. A number of reviewed articles showed that the main bioactive compounds determining the nutritional quality of berries are polyphenols, anthocyanins, and flavonoids [2, 4, 23-28]. The high anthocyanin content and biological activities of these fruits indicate that their consumption would be beneficial to health. The berries may be useful in the production of functional foods containing an efficacious dose of anthocyanins [2].
Our results were in accordance with the studies of Basu et al. [4], based on the high amount of phenolics in cranberries. As it was mentioned above, Borges et al. [5] showed that FRAP, vitamin $\mathrm{C}$, and polyphenolic compounds have similar results, especially in the relationship between the anthocyanins which were the major contributor to the antioxidant capacity of blueberries, whereas the lower TAC of cranberries was due mainly to a reduced anthocyanin content. Vitamin $\mathrm{C}$ was responsible for 18-23\% of the TAC of cranberries, but did not contribute 
to the TAC of the blueberry extract. Our results on antioxidant capacity of gooseberry correspond with Puente et al. [6] and Erkaya et al. [25], who showed that addition of gooseberry in the concentration of $15 \%$ to ice cream positively influenced the chemical, sensory, and mineral characteristics of the mixture.

The comparison of the results of different solvents in Dabai fruit parts (methanol, ethanol, ethyl acetate, acetone, and water) and total phenolics, total flavonoids, total anthocyanins, and antioxidant capacity ABTS $^{+}$and FRAP assays) were in accordance with our data [10]. The acetone extract had maximum phenol and flavonoid content and showed best DPPH free radical scavenging activity and reducing capacity assessment. Ethyl acetate extract showed best superoxide radical scavenging activity, while aqueous extract showed best hydroxyl radical scavenging activity [9]. Our present results correspond with the previous ones where the amount of polyphenol compounds and their antioxidant capacities of Murtilla berries were significantly higher than in other studied berries and are comparable with blueberries [11]. In our recent research, Myrteola nummularia, Murtilla, blueberries, raspberries, and black chokeberries were compared [11].

It was evaluated that the ability to inhibit LDL oxidation and total polyphenol content were consistent in classifying the antioxidant capacity of the polyphenol-rich beverages in the following order: blueberry juice $>$ black cherry juice, acai juice, cranberry juice $>$ orange juice [29]. This order is in agreement with the polyphenol and antioxidant ability of blueberry and cranberry data in our investigation. Some studies contribute to the pharmacologic knowledge of Physalis peruviana regarding a remedy commonly used in Colombian traditional medicine [30]. Our results in vitro studies were compared with Faria et al. [31] and Hurst et al. [32], where anthocyanin-derived blueberry extracts were analyzed for the contents of polyphenols, flavonoids, anthocyanins, and anthocyanin-derived pigments. All of the extracts provided the protection of membranes against peroxyl radicals by increasing the induction time of oxidation. This effect increased with the polyphenol content and with the structural complexity of the anthocyanin-derived pigments of the extracts. Our results are in correspondence with Burdulis et al. [24], where it was shown that the strongest antioxidant capacity possesses blueberry cultivar "Berkeley" $(82.13 \pm 0.51 \%)$. Our results about the investigated berries like cranberries are in full correspondence with other reports that it is an excellent source of high-quality antioxidants and should be examined in human supplementation studies [33]. Bog bilberry water extracts contained polyphenol, anthocyanin-rich (pigment), and sugar/acid fractions by using ethyl acetate, acidic methanol $(\mathrm{MeOH})$ and $0.01 \mathrm{~N} \mathrm{HCl}$. The crude extract and fractions containing polyphenol and pigment exhibited the greatest antioxidant activities with $50 \%$ inhibitory concentration IC(50) values of $85.8,33.2$, and $16.7 \mu \mathrm{g} / \mathrm{mL}$, respectively, for the DPPH assay, and $48.1,83.8$, and $51.9 \mu \mathrm{g} / \mathrm{mL}$ for the nonenzymatic superoxide radical assay. In our case, the highest antioxidant capacity was shown in water; therefore, for binding properties were used only these extracts [34]. The amount of total phenolics, anthocyanins, and ascorbic acid varied in berries depending on their maturity and varieties. Our results were in agreement with others [35], who showed the variation in their composition. The phenolic compounds were about $504 \mathrm{mg} / 100 \mathrm{~g}$. The biggest quantities of ascorbic acid were found in the ripe berries of "Ben Lear" cultivar $(15.8 \mathrm{mg} /$ $100 \mathrm{~g}$ ). Based on the data reported by Wolfe and Liu [36], quercetin had the highest cellular antioxidant activity (CAA) value, followed by kaempferol, epigallocatechin gallate (EGCG), myricetin, and luteolin among the pure compounds tested. Among the selected fruits tested, blueberry had the highest CAA value, followed by cranberry $>$ apple $=$ red grape $>$ green grape. Our results are similar to Kusznierewicz et al. [37], where the antioxidant activities of different blue-berried honeysuckle cultivars were similar to that of wild-growing bilberries (ranging from 170 to 417 $\mu \mathrm{mol} \mathrm{TE} / \mathrm{g}$ DW in ABTS and from 93 to $166 \mu \mathrm{mol} \mathrm{TE} / \mathrm{g}$ DW in DPPH and Folin-Ciocalteu tests). The major anthocyanin in the blue-berried honeysuckle was cyanidin-3-glucoside, which constituted $84-92 \%$ of the total anthocyanins. Our data can be comparable with another report [38], where the proanthocyanidins (condensed tannins) were present in the blackberry fruits. The average anthocyanin concentration was $49.2 \mathrm{mg} / \mathrm{g}$ in the commercial cultivar 'Tupy' while in the wild genotypes and the breeding line, the range was 361.3-494.9 mg/g (cyanidin 3-O-glucoside equivalent). The proanthocyanidin concentration varied widely among wild genotypes (417.5-1,343.6 mg/g CE). Comparison of different fractions of water extracts from wild blackberry Aristotelia chilensis (Mol) Stuntz (Elaeocarpaceae) corresponded with our results. Also, other authors reported similar results [39]. Total phenolics, flavonoids, and anthocyanins (mg/g FW) were in blueberry 261-585, 50, 25-495; raspberry 121, 6, 99; antioxidant activity ( $\mu \mathrm{mol}$ Trolox/g FW for blueberry 14 by ABTS and 25.3 by DPPH) [39]. The result from this study indicated that blueberries had very high ORAC values and higher antioxidant capacity than other selected fruits and vegetables.

In the present report, the best binding ability to the HSA was with water extracts of berries. It is interesting that in Faria et al. [31], the antiradical properties and the reducing power of the extracts by using DPPH and FRAP methods, respectively, were in agreement with those obtained with the liposome membranes. This is in accordance with our present data that the binding properties and the antioxidant capacities are in correlation. A blueberry fruit extract displayed a potent and significant dose-dependent protective 
capacity as it was shown in fluorescence studies with binding with HSA [32]. The obtained results by fluorescence are in direct relationship with the antioxidant properties of the berries extracts. The synergism of bioactive compounds is shown when to the mixture of HSA and berries extracts caffeic acid was added. Our very recent results showed that the fluorescence is significantly quenched, because of the conformation of the HSA changes in the presence of phenolic acids and berries extracts. This interaction between phenolic acids and HSA was investigated using tryptophan fluorescence scavenging. Other results $[14,22]$ differ from the reported by us, probably because of the variety of antioxidant abilities of pure phenolic acids and different ranges of fluorometry scanning used in a similar study. In vitro results of interaction of HSA and caffeic acid shown in the present study can be compared with other reports [22]. The displacement experiments confirmed that caffeic acid could bind to the site I of HSA, which was in agreement with the result of the molecular modeling study [22]. There are not too many applications of 3D fluorescence spectra; therefore, our present conclusions that 3-D fluorescence can be used as an additional tool for the characterization of the extracts of berries cultivars correspond with the previous data [15]. The matching results of common peaks for the first time showed that FTIR spectra can be used for a rapid estimation of extracted bioactive compounds. Quercetin and hesperidin exhibited the highest matching of the peaks in the investigated berries extracts in comparison with fisetin, caffeic, and gallic acids. In our previous study, the FTIR spectra data showed that the main bands in the berries samples slightly shifted [15]. A shift in the difference between the standards and the investigated samples can be explained by the extraction procedures of the main polyphenols.

In conclusion, the bioactivity of blueberries is significantly higher than the bioactivity of other studied samples; however, this index in the gooseberries is comparable with blueberries and cranberries. The binding properties of the investigated samples are in correlation with the antioxidant capacity. 3-D fluorescence and FTIR spectroscopy were used as an additional tool for the characterization of the polyphenol extracts in different berries cultivars. The analytical methods used in this study can be applied for any of the food analysis.

\section{Conflict of interest None.}

Compliance with Ethics Requirements This article does not contain any studies with human or animal subjects.

Open Access This article is distributed under the terms of the Creative Commons Attribution License which permits any use, distribution, and reproduction in any medium, provided the original author(s) and the source are credited.

\section{References}

1. Wu X, Beecher GR, Holden JM, Haytowitz DB, Gebhardt SE, Prior RL (2006) Concentrations of anthocyanins in common foods in the United States and estimation of normal consumption. J Agric Food Chem 54:4069-4075

2. Bowen-Forbes CS, Zhang Y, Nair MG (2010) Anthocyanin content, antioxidant, anti-inflammatory and anticancer properties of blackberry and raspberry fruits. J Food Compos Anal 23:554-560

3. Poltanov EA, Shikov AN, Dorman HJ, Pozharitskaya ON, Makarov VG, Tikhonov VP, Hiltunen R (2009) Chemical and antioxidant evaluation of Indian gooseberry (Emblica officinalis Gaertn., syn. Phyllanthus emblica L.) supplements. Phytotherapy Res 23:1309-1315

4. Basu A, Betts NM, Ortiz J, Simmons B, Wu M, Lyons TJ (2011) Low-energy cranberry juice decreases lipid oxidation and increases plasma antioxidant capacity in women with metabolic syndrome. Nutrition Res 31:190-196

5. Borges G, Degeneve A, Mullen W, Crozier A (2010) Identification of flavonoid and phenolic antioxidants in black currants, blueberries, raspberries, red currants, and cranberries. J Agric Food Chem 58:3901-3909

6. Puente LA, Pinto-Muñoz CA, Castro ES, Cortés M (2011) Physalis peruviana Linnaeus, the multiple properties of a highly functional fruit: a review (Review). Food Res Int 44:1733-1740

7. Ramadan MF (2011) Bioactive phytochemicals, nutritional value, and functional properties of cape gooseberry (Physalis peruviana): an overview (Review). Food Res Int 44:1830-1836

8. Hassanien MFR (2011) Physalis peruviana: a rich source of bioactive phytochemicals for functional foods and pharmaceuticals (Review). Food Rev Int 27:259-273

9. Chanda SV, Kaneria MJ (2012) Optimization of conditions for the extraction of antioxidants from leaves of Syzygium cumini L. using different solvents. Food Anal Methods 5:332-338

10. Khoo HE, Azlan A, Ismail A, Abas F (2012) Influence of different extraction media on phenolic contents and antioxidant capacity of defatted Dabai (Canarium odontophyllum) fruit. Food Anal Methods 5:339-350

11. Arancibia-Avila P, Toledo F, Werner E, Suhaj M, Leontowicz H, Leontowicz M, Martinez-Ayala AL, Pasko P, Gorinstein S (2011) Partial characterization of a new kind of Chilean Murtilla-like berries. Food Res Int 44:2054-2062

12. Benzie IFF, Strain JJ (1996) The ferric reducing ability of plasma (FRAP) as a measure of 'antioxidant power': the FRAP assay. Anal Biochem 239:70-76

13. Re R, Pellegrini N, Proteggente A, Pannala A, Yang M, RiceEvans C (1999) Antioxidant activity applying an improved ABTS radical cation decolorization assay. Free Radical Biol Med 26:1231-1237

14. Xiao JB, Mao FF, Yang F, Zhao YL, Zhang C, Yamamoto $\mathrm{K}$ (2011) Interaction of dietary polyphenols with bovine milk proteins: molecular structure-affinity relationship and influencing bioactivity aspects. Mol Nutr Food Res 55:1637-1645

15. Gorinstein S, Haruenkit R, Poovarodom S, Vearasilp S, Ruamsuke P, Namiesnik J, Leontowicz M, Leontowicz H, Suhaj M, Sheng G-P (2010) Some analytical assays for the determination of bioactivity of exotic fruits. Phytochem Anal 21:355-362

16. Sanz M, Cadahia E, Esteruelas E, Munoz AM, Simon BF, Hernandez T, Estrella I (2010) Phenolic compounds in cherry (Prunus avium) heartwood with a view to their use in cooperage. J Agric Food Chem 58:4907-4914

17. Singleton VL, Orthofer R, Lamuela-Raventos RM (1999) Analysis of total phenols and other oxidation substrates and antioxidants by means of Folin-Ciocalteu reagent. Methods Enzymol 299:152-178 
18. Ozyurek M, Guclu K, Bektasoglu B, Apak R (2007) Spectrophotometric determination of ascorbic acid by the modified CUPRAC method with extractive separation of flavonoids-La (III) complexes. Anal Chim Acta 588:88-95

19. Cheng GW, Breen PJ (1991) Activity of phenylalanine ammonialyase (PAL) and concentrations of anthocyanins and phenolics in developing strawberry fruit. J Am Soc Hortic Sci 116:865-869

20. Barroso MF, Noronha JP, Delerue-Matos C, Oliveira MBPP (2011) Flavored waters: influence of ingredients on antioxidant capacity and terpenoid profile by HS-SPME/GC-MS. J Agric Food Chem 59:5062-5072

21. Wulf JS, Geyer M, Nicolai B, Zude M (2005) Non-destructive assessment of pigments in apple fruit and carrot by laser-induced fluorescence spectroscopy (LIFS) measured at different time-gate positions. Acta Horticulturae (Proceedings of the 5th International Postharvest Symposium) 2: 1387-1393

22. Zhang Y, Yue Y, Li J, Chen X (2008) Studies on the interaction of caffeic acid with human serum albumin in membrane mimetic environments. J Photochem Photobiol B 90:141-151

23. Sinelli N, Spinardi A, Di Egidio V, Mignani I, Casiraghia E (2008) Evaluation of quality and nutraceutical content of blueberries (Vaccinium corymbosum L.) by near and mid-infrared spectroscopy. Postharvest Biol Technol 50:31-36

24. Burdulis D, Sarkinas A, Jasutiene I, Stackevicene E, Nikolajevas L, Janulis V (2009) Comparative study of anthocyanin composition, antimicrobial and antioxidant activity in bilberry (Vaccinium myrtillus L.) and blueberry (Vaccinium corymbosum L.) fruits. Acta Pol Pharm 66:399-408

25. Erkaya T, Dademir E, Sengül M (2012) Influence of Cape gooseberry (Physalis peruviana L.) addition on the chemical and sensory characteristics and mineral concentrations of ice cream. Food Res Int 45:331-335

26. Dueñas M, Surco-Laos F, González-Manzano S, González-Paramás AM, Santos-Buelga C (2011) Antioxidant properties of major metabolites of quercetin. Eur Food Res Technol 232: 103-111

27. Zhang L, Zhou J, Liu H, Khan MA, Huang K, Gu Z (2012) Compositions of anthocyanins in blackberry juice and their thermal degradation in relation to antioxidant activity. Eur Food Res Technol 235:637-645

28. Valcheva-Kuzmanova S, Marazova K, Krasnaliev I, Galunska B, Borisova P, Belcheva A (2005) Effect of Aronia melanocarpa fruit juice on indomethacin-induced gastric mucosal damage and oxidative stress in rats. Exp Toxicol Pathol 56:385-392
29. Seeram NP, Aviram M, Zhang Y, Henning SM, Feng L, Dreher M, Heber D (2008) Comparison of antioxidant potency of commonly consumed polyphenol-rich beverages in the United States. J Agric Food Chem 56:1415-1422

30. Pardo JM, Fontanilla MR, Ospina LF, Espinosa L (2008) Determining the pharmacological activity of Physalis peruviana fruit juice on rabbit eyes and fibroblast primary cultures. Invest Ophthalmol Vis Sci 49:3074-3079

31. Faria A, Oliveira J, Neves P, Gameiro P, Santos-Buelga C, de Freitas V, Mateus N (2005) Antioxidant properties of prepared blueberry (Vaccinium myrtillus) extracts. J Agric Food Chem 53:6896-6902

32. Hurst RD, Wells RW, Hurst SM, McGhie TK, Cooney JM, Jensen DJ (2010) Blueberry fruit polyphenolics suppress oxidative stress-induced skeletal muscle cell damage in vitro. Mol Nutr Food Res 54:353-563

33. Vinson JA, Bose P, Proch J, Al Kharrat H, Samman N (2008) Cranberries and cranberry products: powerful in vitro, ex vivo, and in vivo sources of antioxidants. J Agric Food Chem 56:58845891

34. Kim YH, Bang CY, Won EK, Kim JP, Choung SY (2009) Antioxidant activities of Vaccinium uliginosum L. extract and its active components. J Med Food 12:885-892

35. Viskelis P, Rubinskiene M, Jasutiene I, Sarkinas A, Daubaras RC (2009) Anthocyanins, antioxidative, and antimicrobial properties of American cranberry (Vaccinium macrocarpon Ait.) and their press cakes. J Food Sci 74:C157-C167

36. Wolfe KL, Liu RH (2007) Cellular antioxidant activity (CAA) assay for assessing antioxidants, foods, and dietary supplements. J Agric Food Chem 55:8896-8907

37. Kusznierewicz B, Piekarska A, Mrugalska B, Konieczka P, Namiesnik J, Bartoszek A (2012) Phenolic composition and antioxidant properties of Polish blue-berried honeysuckle genotypes by HPLC-DAD-MS, HPLC postcolumn derivatization with ABTS or FC, and TLC with DPPH visualization. J Agric Food Chem 60:1755-1763

38. Cuevas-Rodriguez EO, Yousef GG, Garcia-Saucedo PA, LopezMedina J, Paredes-Lopez O, Lila MA (2010) Characterization of anthocyanins and proanthocyanidins in wild and domesticated Mexican blackberries (Rubus spp.). J Agric Food Chem 58: 7458-7464

39. Li W, Hydamaka AW, Lowry L, Beta T (2009) Comparison of antioxidant capacity and phenolic compounds of berries, chokecherry and seabuckthorn. Cent Eur J Biol 4:499-506 